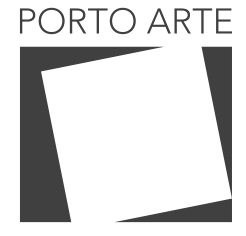

Revista de Artes Visuais

, 25 n. 44 $\mathrm{Jul} / \mathrm{dez} 2020$ e-ISSN: 2179-8001

\title{
"Esquina do Mundo", a quarentena de um hospital de cuidados paliativos
}

"World's corner", the quarantine of a palliative care hospital

\section{Denise Bernuzzi Sant'anna}

ORCID: 0000-0003-3613-9322

Pontifícia Universidade Católica de São Paulo, Brasil

\section{Manuela Samir Maciel Salman}

Hospital Premier, Brasil

\section{Maria Goretti Maciel}

Instituto Paliar, Brasil

\section{Peter Pál Pelbart}

ORCID:0000-0003-1880-0113

Universidade Católica de São Paulo

\section{Samir Salman}

Hospital Premier

\section{Resumo}

Esta é a transcrição da conversa sobre o filme "Esquina do Mundo". Esta conversa mergulha em reflexões coletivas e meditações de processos de cuidado radical em um hospital de cuidados paliativos em São Paulo, Brasil, dentro da atual crise covid-19. Investiga formas de resistência transversal na ecologia de uma instituição como um hospital e descreve algumas das práticas que são implementadas em conjunto com a enfermagem, como práticas criativas.

Palavras-chave

Cuidado coletivo. Covid-19. Pandemia. Transversalidade. Morte.

\section{Abstract}

This is the transcript of the conversation/presentation about the film "Esquina do Mundo" (World's corner). This conversation dives around collective reflections and meditations of processes of radical care at a palliative care hospital in São Pau10, Brazil, within the current covid-19 crisis. It investigates forms of transversal resistance within the ecology of an institution such as a hospital, and describes some of the practices that are implemented together with nursing, such as creative practices.

Key-words 


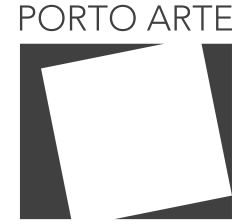

Revista de Artes Visuais

Figura 1: Visita a paciente internada no Hospital Premier proporcionada pela "Janela dos encontros" criada pelo hospital. Still do Filme "Esquina do mundo", 2020. (Direção de João Rocha Rodrigues)

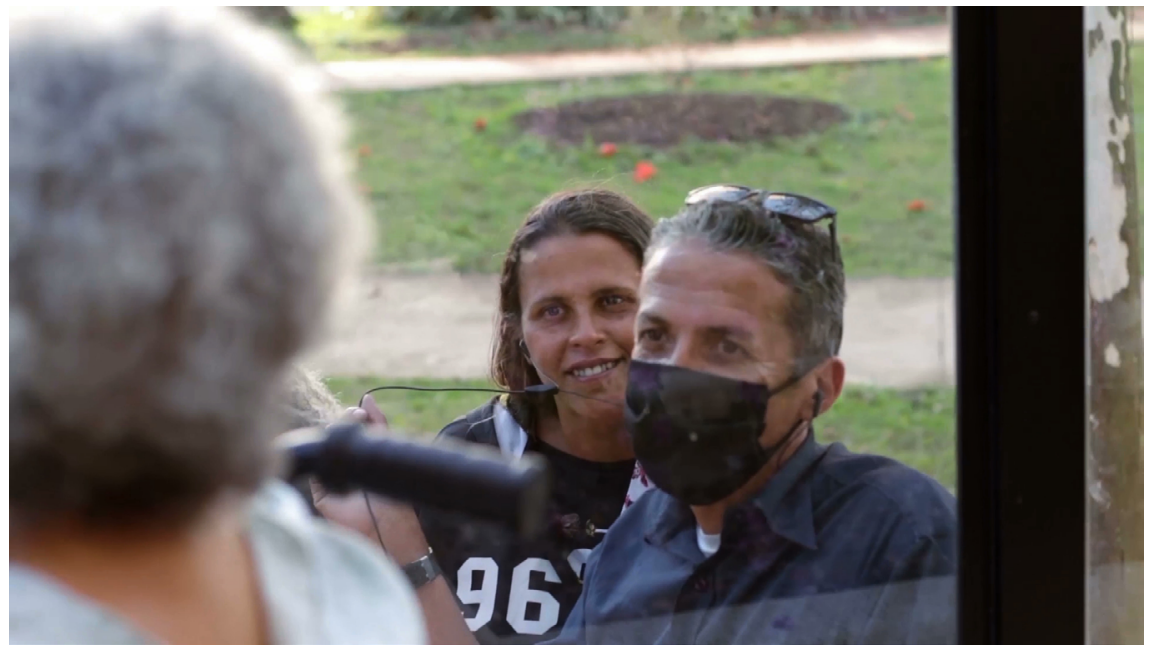

Maria Goretti Maciel:

Muito boa tarde a todos e a todas que nos assistem. ${ }^{1}$ Esse é o canal do Hospital Premier aqui em São Paulo. E hoje, segundo sábado do mês de Outubro de 2020, 10 de Outubro de 2020 é o dia em que o Brasil computa 150.000 mortos pela doença chamada Covid-19. 150.000 pessoas morreram no país desde Março deste ano. 150.000 vítimas dessa doença. 150.000 pessoas que não tiveram a devida proteção ou mesmo protegidas foram vítimas. A gente tem certeza que a grande maioria dessas pessoas não tiveram acesso ao tratamento e a essa forma de cuidar das pessoas que se chama "cuidados paliativos". Todo ano no segundo sábado do mês de Outubro o mundo comemora essa área de conhecimento. Hoje é o Dia Mundial de Cuidados Paliativos. Neste dia, em todos os continentes, em cerca de 80 países, o mundo para um pouco para refletir sobre o que podemos fazer para aliviar o sofrimento de pessoas que estão doentes, pessoas que estão vulneráveis, pessoas que estão vulneradas, que podem morrer, que estão sujeitas a morrer dependendo de sua condição e que poderiam ter esse sofrimento aliviado, por uma série de práticas, uma combinação de ações desenvolvidas em sua maioria por profissionais de saúde, mas muitas vezes também por outras pessoas, por músicos, por artistas, filósofos, poetas, pela vida que se tem, para ser aliviada e ser cuidada. Estamos em um lugar que faz isso muito bem. Este hospital é um lugar que protege a vida. É um lugar que cuida da vida e que alivia o sofrimento. A palavra paliar significa proteger, no final das contas. E foi isso que fez esse hospital

\footnotetext{
1 - A conversa aconteceu virtualmente no dia 10 de Outubro de 2020, como parte do lançamento do documentário "Esquina do Mundo" Disponível em <https://youtu.be/PYcRWEQzGTI>Acesso em 14/11/2020. 2- "História dos cuidados paliativos", no site da ANCP (Associação Nacional dos Cuidados Paliativos) Disponível em: <https://paliativo.org.br/cuidados-paliativos/historia-dos-cuidados-paliativos> Acessado em $10 / 10 / 2020$.
} 


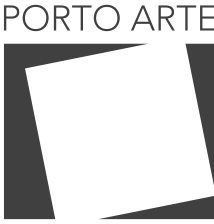

Revista de Artes Visuais

V.25 n.44 Jul/dez 2020 e-ISSN: 2179-8001
Figura 2: Enfermeiro do hospital Premier. Still do Filme "Esquina do mundo", 2020. (Direção de João Rocha Rodrigues

nesses últimos 200 dias de pandemia. ${ }^{3}$ Enquanto 150 mil pessoas morriam "aqui" fora, nenhuma das pessoas que ficou dentro do hospital se contaminou ou sequer adoeceu e, obviamente, ninguém morreu. Este é um hospital que cuida de pessoas muito frágeis, é um hospital que cuida de pessoas gravemente enfermas, e nenhuma delas adoeceu. Nenhum profissional adoeceu. Todos eles tem uma história muito linda para contar pra todos nós e ensinamentos que vão ficar para o resto de nossas vidas. Essas histórias e esses ensinamentos estão compiladas em 100 dias, desses duzentos dias. Os 100 primeiros dias dessa ação, que foi um isolamento, que o hospital se propôs como um todo Vai ser contada para nós em segundinhos num documentário que se chama "Esquina do Mundo". O filme acompanha esses primeiros 100 dias de isolamento total do Hospital. Essa foi a proposta, o hospital se isolou completamente, tanto os funcionários, como os pacientes, resolveram impedir que essa doença chegasse até o hospital ${ }^{4}$

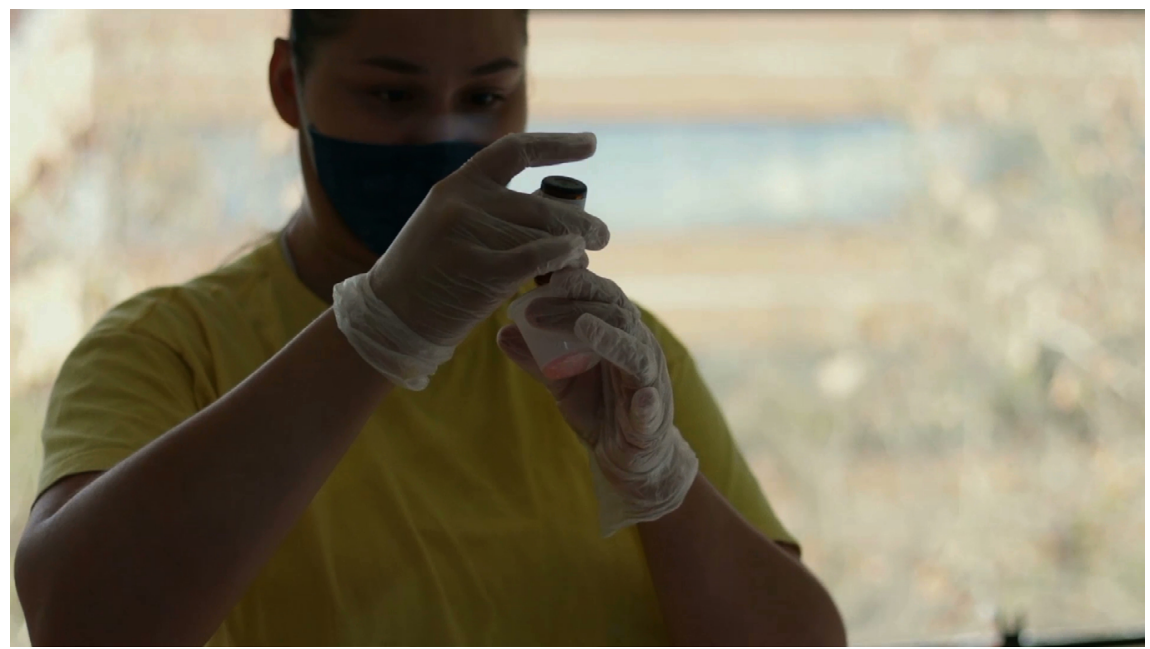

"Aprender a viver, aprender a morrer"

Foi uma prática muito presente no hospital durante muitos anos, a cada segunda feira, na última segunda feira do mês, nós nos reuníamos na Cinemateca Brasileira, aquele espaço lindo aqui em São Paulo, exibíamos um filme que tivesse interesse nosso. As sessões se chamavam Averroes ${ }^{5}$ e tinham como mote "Aprender a viver, apren-

\footnotetext{
3- O novo coronavírus descoberto ainda no final de 2019 na China e causador da doença Covid-19, foi primeiramente detectado na cidade de Wuhan. No Brasil a primeira vítima de Covid-19 foi no dia 12 de Março de 2020, uma mulher negra de 57 anos. Os estados foram decretando fechamentos e restrições cada um à sua forma a partir de meados de 15 de Março. O governo brasileiro foi deficitário em preparar-se para a chegada da pandemia no país, não dispondo de testes, equipamentos ou estrutura hospitalar minimamente suficientes. (nota das Ed.)

4- O documentário Esquina do Mundo foi produzido pela Diorama Cultural, e é um retrato dessa experiência de quarentena do hospital, que foi única no Brasil, dentro do contexto dessa pandemia. Ele foi dirigido por João Rocha Rodrigues, tem roteiro e imagens adicionais da Juliana Dantas, a produção de mais imagens do Ruam Oliveira, outras imagens do Renato Shiruo, trilha sonora do Emiliano Castro, colorização de Humberto Mundim, e som e imagem de Vitor Coroa. O documentário tem duração de 50 minutos.

5- Ibn Rushd ou Averroe (1126-1198) foi teólogo e filósofo islâmico, médico, físico, psicólogo. < https:// en.wikipedia.org/wiki/Averroes> Acessado em 25/10/2020 (nota das Ed.)
} 


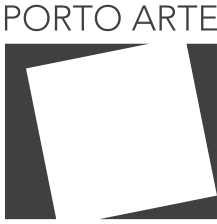

Revista de Artes Visuais

v. $25 n .44$ Jul/dez 2020 e-ISSN: 2179-8001
Figura 3: Paciente e a enfermeira Adriana. Still do Filme "Esquina do mundo", 2020. (Direção de João Rocha Rodrigues) der a morrer". Assim que o filme acabava nos sentávamos e fazíamos uma mesa não de debate, não de discussão, mas sim de reflexão sobre o filme. Então acho que hoje vamos ter a oportunidade de reeditar essa prática, assim que terminar o documentário fiquem ligados porque nós voltaremos para fazer uma reflexão e conversar sobre esse filme com pessoas muito importantes. O Salmir Salman, a médica Manuela Salman, a historiadora Denise Sant'anna, e o filósofo Peter Pál Pelbart. Então vamos à exibição de Esquina do Mundo.

(...)

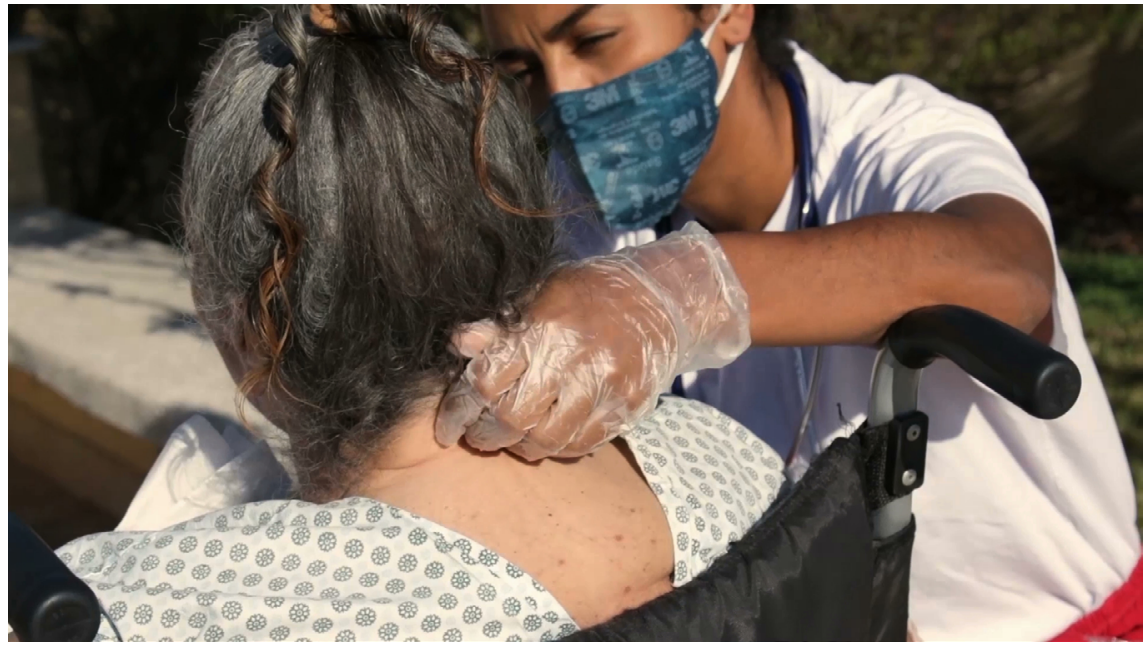

\section{Goretti:}

Pronto, cá estamos nós de volta para nossa mesa de reflexão, e, quanta emoção. Eu ainda estou aqui contendo lágrimas, que acho que são inevitáveis. Eu fui olhar aqui, achei que eu estava muda (...). Eu acho que lágrimas começaram quando eu comecei a ver a janela dos encontros. E eu devo confessar a vocês que estou aqui fora e eu tenho trabalhado na epidemia desde o início, num hospital grande aqui em São Paulo, eu trabalho no Servidor Estadual, de forma muito ativa. Eu tive presente em muitos momentos, e eu tinha, mais do que tudo, entre várias tarefas, a tarefa de ligar para as famílias, fazendo contato com os familiares das pessoas que estavam internadas na UTI, e me deu uma dor no coração porque eu só vi desencontro nesses 180 dias. Eu só vi familiares chorando, pedindo para ver seu familiar pela última vez, pedindo para se despedir daquela pessoa que tava ali, querida, morrendo, e que ela tinha visto pela última vez quando essa pessoa entrou no hospital, às vezes talvez sorridente, às vezes talvez muito bem. E na hora que eu vi a janela do encontro e que eu vi as pessoas se encontrando, podendo falar com seus familiares, me deu um nó. Quantas dessas 150.000 não tiveram essa oportunidade. E tantas coisas mais que esse vídeo nos falou. A gente tem convidados aqui para ouvir, ouvir muitas coisas... 


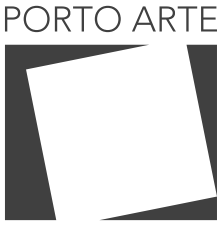

Revista de Artes Visuais

v. 25 ก. 44

$\mathrm{Jul} / \mathrm{dez} 2020$ e-ISSN: 2179-8001

Mas, nossa! Ouvir o Palmério ${ }^{6}$, super ativo no twitter. Ouvir a história dos médicos que se diplomaram técnicos de enfermagem, o quanto isso é importante, o quanto isso é fundamental para nossa carreira, perceber esse dia a dia do cuidado, esse detalhe do cuidado e que muitas vezes o profissional médico não consegue valorizar, entender ou enxergar, o que é o trabalho da enfermagem dentro da coisa toda. 0 trabalho da enfermagem, seja qual for o hospital, é de uma dedicação impressionante, aliás todos os profissionais da área da saúde, que acho que todo hospital nesse momento aprendeu a valorizar um pouco mais."- O cachimbo é alma do velho", que coisa mais linda, perceber as pessoas respeitadas nas suas histórias, nos seus hábitos, nas suas falas; a meta de dez mil calorias do Samir parece que foi cumprida à risca, quanta coisa bonita e quanto amor ali a gente percebeu. 0 que ficou mais impactado pra mim no vídeo foi essa essência do cuidado paliativo, que é uma essência amorosa. E aqui fora a gente viu uma mescla muito grande, a gente viu amor, a gente viu solidariedade, mas a gente viu muita ganância, muito desespero, muitas pessoas preocupadas com o seu mínimo pedaço e muito pouco preocupadas ou muito menos preocupadas com a vida, até mesmo da vida de quem a gente tem que cuidar.

Eu acho que a gente tem candidatos maravilhosos à conversa e eu vou convidar primeiro o Samir. Samir Salman ${ }^{7}$ Samir, conta um pouquinho pra todos nós como você se sentiu nessa responsabilidade de tomar essa decisão e de ser o fio condutor. você é o timoneiro, o condutor dessa nave espacial fora do mundo inteiro que é o Hospital sempre fora do mundo inteiro, e não foi só uma coisa da pandemia não, visto que este o Hospital é um lugar que está fora". Como é que foi viver esses 100 dias, e agora esses 200 dias?

\section{Samir Salman:}

Estou ainda sob o impacto do documentário viu, Goretti? E na verdade ainda estou refletindo sobre tudo isso que aconteceu. Foi intenso. E primeiro eu gostaria de agradecer você que é co-fundadora do Hospital companheira de primeira hora. E agradeço a todos os outros participantes, à Denise Sant'anna, ao Peter Pál Pelbart, à Manuela, e a todos que estão nos assistindo agora. Eu acho que a gente fala muito em valor e a gente teoriza muito modelos de assistência, o fato concreto é que no mês de março deste ano a gente foi confrontado com uma situação dramática. E nesse momento difícil onde a gente percebeu que o que tava em jogo era a vida humana houve um momento de desespero e aflição e foi tomada uma decisão. Eu entendo que a direção deste hospital tem papel na função de apontar caminhos, mas eu quero aqui ressaltar a participação de todos, que sem essa participação de todos os funcionários, as profissionais da limpeza, da cozinha, os médicos, enfermeiros, os fisios, a fono, o assistente social, ... É uma gratidão profunda porque quando nós tomamos a decisão me perguntaram: - Mas quem vai ficar? E eu falei: - Não sei quem vai ficar. Nós não vamos pressionar

\footnotetext{
6- Maria Goretti está comentando sobre uma pessoa que aparece no filme. (nota das Ed.)

7 - Samir Salman é médico e superintendente do hospital. Formado pela Faculdade de Medicina de Itajubá em 1989. Ele também dirige uma vertente educacional e cultural do hospital que foi fundada em Outubro de 2018
} 


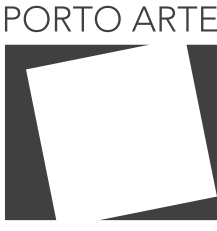

Revista de Artes Visuais

v $25 n .44$

Jul/dez 2020 e-ISSN: 2179-8001

ninguém para ficar, mas diante do fato de que a vida humana tava em risco tanto dos pacientes como dos funcionários, alguma coisa tinha que ser feita. Eu tinha que assumir a responsabilidade de apontar um caminho, e o caminho foi trazer à prática o nosso discurso. Eu entendo que a quarentena solidária foi possível por conta da história, que você pessoalmente ajudou a construir e havia um terreno fértil para que prosperasse uma atitude como essa. Hoje a gente completa 200 dias, a gente flexibilizou a quarentena solidária no dia 2 de Julho e até o momento não temos nenhum caso de pacientes aqui, o que nos alegra muito. A gente continua mesmo depois do dia 2 de Julho com um rigor científico no sentido de prevenção possibilitando que quem tem algum sinal, algum sintoma não entre para trabalhar, e, eu não sei, eu entendo que esse deveria ser o papel de todas as instituições de saúde. Qual a razão de uma instituição de saúde existir, senão promover a saúde e defender a vida? Com a questão da finitude ativa da morte dos cuidados paliativos, por incrível que pareça, foi um hospital de cuidados paliativos que defendeu a vida sem nenhuma concessão. Não houve negociação em nome da segurança. Por que não era só a vida dos pacientes. Mas também a vida dos nossos funcionários que em sua grande maioria ficam no transporte público, entre idas e vindas, eles levam 3 horas, e a gente tem conhecimento que o transporte público é um dos lugares de maior propagação desse vírus. Então nós tínhamos preocupação, não só com o paciente, mas que o funcionário se infectasse e levasse essa doença para casa. Agora imaginar que isso poderia dar certo, como deu, seria muita pretensão. Eu entendo que ter fé em valores é saltar de um picadeiro sem rede, e deixar as forças do universo conspirarem a favor de quem se propõe a defender essa questão da vida humana. Nós continuamos preocupados.

A pandemia arrefeceu mas ela tá dando sinais de volta na Europa, e entendemos que esse é o nosso papel, é o papel da perseverança, de conseguir manter esse tônus da defesa. Estamos cansados, é evidente. Seria muito se através de uma varinha de condão mágica a gente conseguisse retornar ao antigo normal, mas não existe mais isso. Existe um fato concreto que é o risco dessa pandemia. E essa pandemia traz algumas coisas muito interessantes, que exigem da sociedade e especialmente dos profissionais de saúde o compromisso com o outro. Então você imagina, uma sociedade totalmente individualista ser convocada a começar a ter preocupação com o coletivo. Nós estamos no meio dessa aventura e eu posso te dizer o seguinte: faria tudo de novo. E tenho uma gratidão muito profunda por todos que participaram dessa empreitada e estão participando ainda com o cumprimento do seu trabalho. E não há dinheiro que pague o êxito dessa empreitada. este momento a gente tá vivendo um desgoverno, é, na verdade, um momento obscuro da sociedade. A gente corre um risco muito sério de aceitar a possibilidade de minimizar a vida do outro. "Ah! Já que tá doente, é idoso!", e não, não tem isso. Eu só posso te dizer que é muita emoção, é muita gratidão, que eu tenho dentro de mim e agradeço a todos que participaram. Foi um marco para essa instituição, em que ela foi convocada a colocar em prática tudo aquilo que ela preconiza de solidariedade, de humanismo, como diz o ditado popular:- "na hora que a onça foi beber a água a gente viu quem apareceu". E apareceram, foram 94 funcionários que fizeram uma renúncia muito grande de conviver aqui com 


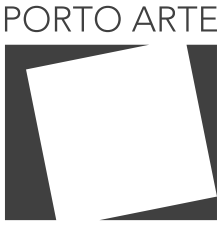

Revista de Artes Visuais

$\vee 25 n .44$

$\mathrm{Jul} / \mathrm{dez} 2020$ e-ISSN: 2179-8001

a gente, internados, junto com os pacientes, na defesa do bem maior que temos, que é a vida humana. Nós não podemos em nenhum momento imaginar que a vida humana pode ser precificada ou ter um valor utilitário que pode se calcular, como um processo de minimizar, ou aceitar, ou naturalizar que o paciente possa partir antes já que ele tem várias comorbidades. E eu entendo que este hospital frutificou, ele já tinha um terreno fértil, a gente já trabalhava muito fortemente com esses valores, e conseguimos colocar em prática. Então é de profunda alegria estar aqui, só tenho a agradecer a todos em nome de seus pacientes e de seus companheiros de trabalho.

\section{Goretti:}

Muito bom Samir, muito bonito. A gente vai ter que ter horas e horas depois pra conversar e contar todos os detalhes, que a gente vai querer ouvir todos. Mas eu vou querer ouvir um pouquinho a Manu, pra gente ter tempo de ouvir todos e poder trocar ainda algumas ideias. Manuela Salman ${ }^{8}$ é uma pessoa importantíssima nas nossas vidas aqui. Ela é facilitadora do programa QELCA que é uma parceria do Hospital com o St. Christophers Hospice (que é o berço no mundo do cuidado paliativo. Ela é pós-graduada em cuidados paliativos). Manu, você é da casa e você teve a brilhante tarefa de ficar fora de casa, fora do hospital, uma aflição eu imagino, fora do hospital. Você foi o coração de toda a operação, você conseguiu de fora ser a ponte e o coração da operação, eu te vi estudando muito, buscando conhecimento. E como é que foi essa experiência de estar dentro e estar fora ao mesmo tempo, de ser essa ponte entre quem estava lá no hospital e o mundo aqui fora. Como é que foi organizar tudo isso?

\section{Manuela Salman:}

Muito obrigada pela sua generosidade, Goretti. Pela apresentação. E também estou aqui sob o impacto do documentário, revivendo todas essas emoções. De fato foi bastante emocionante revisitar tudo isso e, claro, posso qualificar sim toda essa experiência. Não pude participar presencialmente pois eu tenho uma bebê, eu ainda amamento. Mas procurei ter a participação mais ativa possível durante todo esse processo e ajudar com essa questão técnica e acompanhando todas as fontes de informação principais, nacionais e internacionais a respeito da COVID-19. E montando toda a parte administrativa e de segurança para ajudá-los nessa empreitada de sucesso, sob o impacto de quase 200 dias agora que a gente vem atravessando essa pandemia e ainda sem nenhum caso suspeito de COVID entre os pacientes. Confesso que eu não fico muito confortável com a minha exposição (no filme), eu prefiro ficar mais comedida, mas tento deixar essas questões pessoais de lado e é isso. Foi bastante difícil para todo mundo, diante de uma pandemia, sob a responsabilidade de cuidados de pessoas, e pessoas tão frágeis como as que a gente tem no hospital. E também pensando como o Robson falou, nas vidas não só dos pacientes ali internados mas nas vidas dos

\footnotetext{
8- Manuela Salman é médica especializada em psiquiatria, é supervisora clínica do Hospital Premier e é coordenadora do Instituto Premier Educação e Cultura. Um programa que se chama "Cuidados paliativos: um modelo de atenção integral à saúde", pela Faculdade de Medicina de Itajubá, junto com o Hospital Premier e é pós-graduada em Medicina Paliativa pelo Instituto Paliar do Centro Universitário São Camilo.
} 


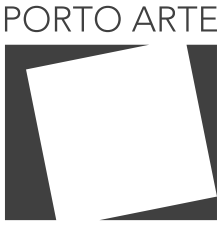

Revista de Artes Visuais

$25 n-44$ $\mathrm{Jul} / \mathrm{dez} 2020$ e-ISSN: 2179-8001

profissionais de saúde, na vida dos familiares desses profissionais. Quer dizer, como o José falou, algo em torno de 500 vidas mais ou menos que se traduz, se você for contar a rede total das pessoas. Então, é um processo muito tenso, óbvio, diante dessa responsabilidade, mas também uma gratidão e um sentimento de tranquilidade por ter conseguido atingir o objetivo principal, para que as pessoas continuem falecendo. Respeitar a morte como algo natural, mas não ser o momento natural. Não deixar que algo externo como a COVID-19 pudesse estar levando a uma morte antecipada de alguém.

\section{Goretti:}

Que bom, Manu. Você está sempre aqui. Bom, nós vamos convidar a Denise Sant'Anna. A Prof ${ }^{a}$ Denise Sant'Anna ${ }^{9}$. E eu fico imaginando, Denise, porque esse documentário é histórico. Muda toda a visão, a perspectiva, a história do que a gente entende por prover serviços de saúde. Eu não sei se você concorda, mas eu queria muito te ouvir, porque você deve ter um cabedal de conhecimento bárbaro para estar aqui comentando conosco. A palavra é sua.

\section{Denise Sant'Anna:}

Obrigada, Goretti, obrigada a vocês todos por poder dividir com vocês esse momento. Estou muito emocionada, e tudo o que eu puder falar é muito pouco perante tudo o que vocês fizeram. Eu estava aqui pensando que a minha quarentena foi tão pobrezinha perto desta, e eu acho que o hospital conseguiu fazer uma coisa interessantíssima. Muitas, mas uma que eu nunca tinha pensado é assim: mesmo na história, quando você fala em quarentena, dá a ideia de uma lacuna, de uma pausa, pára tudo. Muita gente teve que encarar essa e é muito difícil. Então a rotina não é mantida, aí você fica meio perdido dentro de casa, a casa vira uma prisão... Você começa a brigar com as pessoas, você está sozinho... Todo mundo sabe que quarentena no Brasil é um privilégio, porque nem todo mundo tem casa. Mas quem tem casa passou por um momento muito duro aí porque é como se a vida perdesse a densidade. Ora bolas, a quarentena do Premier foi tão intensa, olha, eu devo confessar que eu fiquei com uma inveja de não estar lá. Eu sei que foi difícil, das dificuldades eu posso bem imaginar, mas claro que havia um solo fértil, eu vou falar dele até porque eu conheci um pouco esse trabalho, mas vocês viveram algo inédito no mundo quase. Não sei se houve experiência assim, eu acho que mesmo que tenha ocorrido vocês provaram que no momento mais inóspito da nossa história, com crise econômica, política, sanitária, psíquica etc. Vocês inventaram uma coisa fantástica, uma experiência que é muito densa de cuidados. 0 hospital às vezes é um lugar muito hostil. Raras vezes ele é hospitaleiro. Hostilidade e hospitalidade, há uma tensão aí entre essas duas coisas. O Premier escapa disso largamente. $O$ Premier é um hospital que cuida; não só contato. $O$ contato é uma coisa muito imediata. Ele cuida. As pessoas são cuidadas. E esse cuidado envolve amor. Eu fiquei com muita saudade de pessoas que conheci, por exemplo eu vi o José falando

9- Denise Sant'anna é livre docente do departamento de História e da pós-graduação em psicologia clínica da PUC-SP. Ela é doutora pela universidade Paris VII e é pesquisadora do CNPq. A Denise se especializou em história da saúde, e possui inúmeros livros sobre a condição corporal contemporânea. 


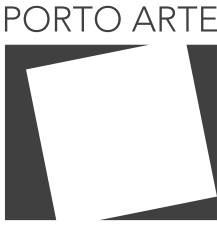

Revista de Artes Visuais

v $25 n \cdot 44$

$\mathrm{Jul} / \mathrm{dez} 2020$ e-ISSN: 2179-8001

aqui da coragem, vem do coração. Então esse cuidado é mesmo um cuidado amoroso. O cuidado implica a meu ver sobretudo convívio. 0 cuidado não é assim uma coisa rápida e fácil. Implica o convívio. E o convívio implica em cultivar coisas. Plantar coisas. Ele implica não só partilhar, ele implica relacionar. A gente está acostumado a falar partilhar porque é uma gíria que está aí na internet: vamos partilhar. Mas é fácil, está aí no Facebook, eu partilho imagens... Aqui não se trata de pôr uma parte, aqui se trata de uma relação com as pessoas. Então assim, eu acho que o que vocês fizeram não tem nome. Tem que inventar um nome para isso, que é simplesmente forte, maravilhoso, e absolutamente necessário. Eu acho que o hospital poderia ser objeto de reflexão para outras instituições não só de saúde, eu acho que extrapola, e mais do que isso. Mas eu volto: o Samir tinha dito que é um terreno fértil. E é mesmo. Eu tive pai e mãe internados aqui. Meu pai ficou dois anos e meio, minha mãe um ano e meio. Eu sou filha única, e ia constantemente ao hospital para visitá-los. Hoje eu me dou conta que era mais que isso, porque a minha mãe tinha Alzheimer. A gente poderia dizer, "ah, porque ela tinha Alzheimer ela esqueceu", porque ela chamava o hospital de "minha casa". Mas eu conhecia bem minha mãe, e ela sentia o hospital como um lar. Lar no sentido etimológico: o lugar da fogueira, o lugar da lareira, o lugar, mais uma vez o coração. E meu pai, que estava bem mais lúcido do que ela, apesar do AVC hemorrágico que ele teve, a única vez que ele precisou sair do hospital foi para fazer um processo cirúrgico em outro hospital, e ele não via a hora de voltar! Ele perguntava assim: "e quando vamos voltar ao hospital?" Ele tinha saudades e falava dos enfermeiros e enfermeiras como se fossem pessoas que ele já conhecia há muito tempo. E hoje eu entendo isso. Por que você fala de alguém como se você conhece há muito tempo? É porque teve uma relação de fato. Não é? Não é só uma conversinha protocolar. Aliás, o hospital, como todo hospital ou toda instituição tem protocolos, tem normas, mas ele é aberto à invenção de protocolos. Ele não é uma instituição de velhos, olha que paradoxo. Ele acolhe um monte de gente idosa. Eu prefiro falar velho do que idoso, acho idoso uma palavra meio feia, mas enfim. Acolhe um monte de velhinhos, velhonas, super velhos, não é? Mas ele não é velho. Por que ele não é velho? Porque ele inventa. Velho é aquele que não inventa mais nada, não é? E as pessoas que estão aí, mesmo como pacientes elas são incitadas a isso. Então eu acho - e a Manuela é especialista no assunto - que a ideia central dos cuidados paliativos está totalmente dentro desse hospital. Porque é viver, até o último momento. Não é esperar a morte. Não é um lugar em que você espera a morte. Eu acho até que os paciente esquecem, como se fossem jovens, que a gente vai morrer. E no bom sentido do termo que estou falando isso. Não é denegar a morte, é que nós estamos vivendo tantas outras coisas. Me lembro da minha mãe. Ela passava batom, e gostava de uma série de atividades, ver pessoas, ia para o jardim... Nunca vou me esquecer do jardim, tão importante para esses pacientes. E eu que acho na verdade, resumindo, vocês criaram uma comunidade que não é só resistente, mas inventiva, absolutamente juvenil nesse sentido. De criação, de aventura, de coragem. É coisa de jovem isso, não é? E vocês fizeram isso. Então, a minha inveja é que agora eu quero ir não é para esperar a morte, eu quero ir aí para rejuvenescer com vocês. É uma comunidade que me dá muito entusiasmo, que me mostra que vale a pena acreditar em invenções dentro desse 


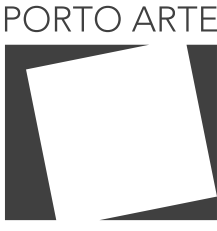

Revista de Artes Visuais

$\vee 25 n .44$

$\mathrm{Jul} / \mathrm{dez} 2020$ e-ISSN: 2179-8001

país. Também é isso, porque o hospital não deixa de estar no Brasil. Então eu acho que ele nos dá aqui uma injeção de ânimo e de realidade. É um lugar que reúne ciência, que é uma coisa assim fria, né? Ciência médica com amor, com invenção, com um certo frescor juvenil. E eu acho que o Samir encarna isso muito quando ele faz todas essas brincadeiras, não é? Do colesterol, da comida etc. É isso. 0 hospital é isso. Vocês estão muito de parabéns. Eu tenho muita saudade. Quando acabar essa história de máscara e pandemia - porque vai daqui a um ano, dois, não sei - eu vou aí fazer uma visita para vocês. Eu fico muito feliz. Obrigada, viu?

\section{Goretti:}

Obrigada, Denise, pelos comentários carinhosos. Todos nós temos um carinho enorme porque essa é uma casa que reinventa a história da medicina. Reinventou-se. Ela reinventou desde o começo, desde o primeiro momento ela sempre foi um lugar muito à frente do tempo. E agora com essa pandemia, pela forma como se articulou, com essa convivência com tudo acho que trouxe mudança nas relações para as pessoas que trabalham na saúde. Muito lindo. Vamos ouvir a voz do filósofo Peter Pál Pélbart ${ }^{10}$. Peter, quanto a gente tem para filosofar sobre tudo e que documentário, e que história de virar o mundo de pernas para cima, porque para baixo as pernas já são. Conta para a gente como é que esse documentário impactou você e o que você pensa de tudo isso.

\section{Peter Pál Pélbart:}

Puxa vida. Eu estou perplexo. Acho que não é apenas uma experimentação coletiva, mas é uma revolução numa escala diminuta de uma audácia, de uma coragem e de uma aposta afetiva raríssimas. 0 que foi feito aí, eu diria assim, o Samir, que é um personagem único, uma figurassa, ele quando decide, como ele contou, tanto no filme quanto na conversa dele aí, quando ele decidiu de uma hora para outra fechar, foi uma espécie de gesto em que eu estou de acordo com ele, esse grau de aposta convoca as forças do universo para conspirarem a favor. E esse tipo de decisão radical tem uma potência de disseminação, como um vírus, mas no sentido contrário. Quer dizer, o Samir contaminou todo mundo nessa mobilização afetiva absoluta e eu acho que o que vocês viveram aí nesses meses, eu diria assim, as hierarquias que se embaralharam, os protocolos que foram revirados... Aquilo que lá fora era proibido, de ficar perto, de se abraçar, de se relacionar, eram a condição de possibilidade dessa experiência ali dentro. Então, vocês viveram uma espécie de comunismo afetivo no sentido mais extremo da palavra. E para mim, eu tenho aí um cunhado, e tenho uma irmã que frequenta muito aí, eu sei um tanto do que acontece ali e o quanto que a vida deles foi salva por esse ambiente, essa atmosfera, esse cuidado, essa delicadeza, essa atenção com cada singularidade. Tudo bem, vocês são um hospital de cuidados paliativos, mas eu acho que tem muito mais coisa aí. Vocês ousaram nessa aventura, e eu acho que ela tem uma força de exemplo que vai muito além, também, claro, dos cuidados paliativos dos

10- Peter Pál Pélbart é professor do departamento de Filosofia e do Núcleo de Estudos da Subjetividade na pós-graduação em Psicologia Clínica da PUC-SP. Ele é um estudioso da obra do Gilles Deleuze, estudo francês, e traduziu para o português Conversações, Crítica e Clínica, e parte de Mil Platôs do Deleuze. 


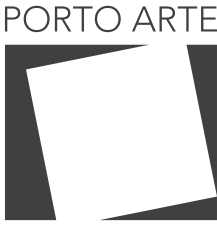

Revista de Artes Visuais

v. 25 n. 44

$\mathrm{Jul} / \mathrm{dez} 2020$ e-ISSN: 2179-8001

hospitais, da saúde, das instituições. E contrasta absolutamente com o que a gente vive hoje no Brasil, onde o perigo maior eu não sei está no vírus e nos 150 mil mortos, que serão 200 , depois 250 , sei lá, ou se o perigo maior do que nos acontece com o país não é um outro vírus que é o da desafecção. A desafecção, a indiferença, a absoluta denegação do risco, do perigo, da morte, da tragédia. Esse é o grande perigo político, psicopolítico que todos nós vivemos. E a meu ver, o que vocês demonstraram com corpo e alma, com a mão na massa, com o coração batendo, com uma espécie de inteligência coletiva que mobilizou a todos... Vocês demonstraram que uma outra via é possível. E a meu ver, a força de exemplo que vocês carregam é estonteante. $E$ eu gostaria muito de fazer, na medida do que a gente pode, cada um tem a sua parte, é fazer reverberar essa experiência e que ela contamine outras instituições, outros ambientes, outros dispositivos de cuidado. Vocês publicaram um texto no site da nossa editora - a gente tem uma editora chamada $n-1^{11}$ - em que vocês relataram essa experiência. Com categorias mais profissionais, tentando dar um rigor científico, e no documentário a gente vê um outro aspecto também, mas eu estou convencido de que essa experiência ressoa com milhares de outras microexperiências por aí afora e eu espero que isso ganhe uma espécie de quantidade psicopolítica que produza a médio prazo alguma reviravolta num contexto maior. Vocês estão absolutamente deparabéns e eu sou gratíssimo pela existência e por poder estar junto compartilhando esse momento. Era isso.

\section{Goretti:}

Muito obrigada, Peter. O Peter falou uma coisa muito importante, a gente precisa contaminar. Esse vírus afetivo e efetivo do Hospital precisa contaminar o mundo aqui fora. A gente precisa se contaminar de novas práticas. Novas práticas na saúde, novas práticas nas relações interpessoais, novas práticas na educação, em tudo o que a gente vê do mundo. Mas e agora, como a gente faz para contaminar desta experiência esse mundo aqui fora? Além de divulgar loucamente esse vídeo e de poder conversar infinitamente sobre ele? Como que a gente contamina esse mundo aqui fora, não é? 0 que vocês acham? Alguma sugestão?

\section{Peter:}

Vai lá, Samir!

\section{Samir:}

Ah, grande Peter. Eu acho que quando a gente começou isso, e aliás todo o trabaIho do hospital ele é voltado no sentido de dar coerência entre o que é falado e o que é feito. Outro dia eu fui falar em uma universidade, e estudando a minha apresentação eu vi lá "missão", "visão" e "valores". E me deu uma curiosidade de estudar a missão, visão e valores da Vale mineradora. [risos]

\footnotetext{
11- Peter se refere ao texto que Manuela Salman e Amira Adnan Salman escreveram no começo dessa experiência, "Quarentena solidária", publicado junto à coleção Pandemia crítica. Disponível em < https:// www.n-1edicoes.org/textos/95> Acessado em 12/09/2020.
} 


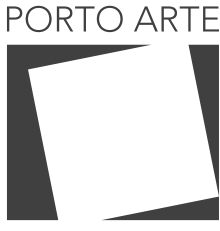

Revista de Artes Visuais

$\vee 25 n .44$

$\mathrm{Jul} / \mathrm{dez} 2020$ e-ISSN: 2179-8001

\section{Goretti:}

Precisamente o contrário, fez o reverso.

\section{Samir:}

E aí eu me surpreendi porque lá tem como um dos valores deles essenciais: "amam a natureza". [risos] Depois, "amam a vida". Aí eu fiquei refletindo durante a madrugada, que deve ter alguma letra minúscula para os acionistas, porque não é possível. Então, eu acho que a gente vive em uma sociedade - Peter é professor de filosofia e pode nos ensinar, e a Denise também, como uma estudiosa - de uma superficialidade onde a versão ganha mais força do que o fato. Então, as pessoas se embalam da responsabilidade social, da responsabilidade humana e não colocam em prática. E o fato concreto é que eu fui criado, eu conheci e me formei em um ambiente em que nós temos que ter coerência entre o que a gente fala e o que a gente faz. Não foi uma decisão fácil, não foi prazerosa, não foi lucrativa - pelo contrário, foi anti-empresarial, mas naquele momento, o que estava em jogo, quando você se confronta com uma situação dessa, foi colocar para fora o que a gente pensa. Então, a gente está vivendo um momento muito duro no mundo, não é só no Brasil não. Onde as elites dominam as narrativas, o Peter pode até falar muito mais sobre isso, mas me preocupa muito esse momento da saúde. Eu vou falar da área em que eu trabalho, que é o momento da medicina mercantilista, então eu acho que essa barreira do respeito à vida humana, se ela cair, nós estamos fadados a desaparecer. Se a vida humana não for considerada um valor intrínseco inegociável, não tem conversa. Nós vamos correr riscos muito sérios. E se você não quer defender nenhum ideal, defenda o seu interesse próprio, porque eu tenho uma notícia triste, você vai envelhecer e você pode ser vítima daquilo que você está vendo hoje nos ambientes hospitalares. Então gente brinca muito, oxalá o hospital sobreviva para que a gente seja cuidado em lugar onde a gente é respeitado minimamente. Eu vejo os hospitais, e dei o exemplo da Vale, nenhum hospital vai colocar lá: "estamos aqui para ganhar dinheiro". Mas se você for a fundo, hoje, quem está assumindo o sistema de saúde brasileiro são fundos de investimento. Caras que vão discutir saúde a partir de um PowerPoint e de lucro. O paciente é um detalhe no esquema. Se ele vai viver... Quer dizer, até onde o capital vai? Nós estamos em uma situação muito complicada. Eu reitero aqui minha gratidão à minha equipe. Quando a decisão foi tomada, eu imaginei que iriam ficar 20 pessoas, e para minha surpresa ficaram 94, e foi em um ambiente muito democrático. Mesmo quem ficou em casa continuou recebendo o seu salário, seus direitos. Porque você não pode convocar as pessoas - Eu fiz questão de discutir essa pré-estreia do documentário com o Peter, com a Goretti, com a Denise, para a gente refletir sobre tudo isso. Tem muitos vieses, ninguém é obrigado a acreditar na idoneidade do empresário, que aqui no caso sou eu. Tem que colocar em prova: venha checar o que está acontecendo, venha ver. Venha ver se é tudo de verdade, não é? Porque senão fica uma coisa, nessa apresentação da Vale mineradora eu convidei as pessoas a refletirem um pouco mais além do que está escrito. Uma mineradora que provocou um acidente, colocando em risco a vida de mais de 200 funcionários que foram mortos... O refeitório foi construído, não por falta de terreno, em um lugar que foi o mais fácil para eles ou o 


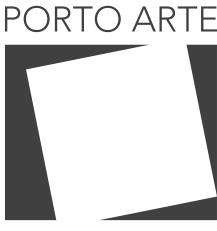

Revista de Artes Visuais

$\vee 25 n .44$

$\mathrm{Jul} / \mathrm{dez} 2020$ e-ISSN: 2179-8001

mais barato, e agora você fica vendo propagandas dizendo "a Vale é responsabilidade social, a Vale ama a vida". Nós estamos vivendo em um mundo muito complicado de valores. $\mathrm{O}$ que são valores? Essa é a grande pergunta. Nós estamos falando do quê? E através do hospital e da minha equipe a gente colocou em prática aquilo que a gente discursa. Não adianta nada falar em defesa da vida e na hora que mais precisava... Nós estamos hoje completando 200 dias sem nenhum caso, mas eu vou falar que no começo foi uma apreensão e uma aflição. Porque imaginem vocês se algum de nós estivesse infectado, como seria isso? 0 ônus e a responsabilidade. Pessoalmente, eu não tive dúvidas. Agora, eu não poderia convocar os funcionários baseado na minha força. Como você pode exigir a mesma força de uma sociedade tão desigual? Funcionários... A gente vai procurar através desse vídeo espalhar esse exemplo. E, para nossa surpresa, está tendo mais repercussão fora do país do que aqui.

\section{Manuela:}

Essa é uma das perguntas que a gente recebeu.

\section{Samir:}

O Hospital vocês três convidados fazem parte de nossa história institucional. E é assim que é a vida. Agora, sem se arvorar de estar certo ou errado, vamos discutir os argumentos. Eu ouvi muitas críticas. E falei: - Mas me diz uma coisa, o que funciona? Não tem vacina. Não tem diagnóstico. "Ah, é só ficar no isolamento social". Então, o que se fazer? É isso.

\section{Goretti:}

Samir, temos duas questões aqui. Duas participações importantes de dois paliativistas. Uma é a Juliana Mandato Ferragut, e ela pergunta o seguinte: "O hospital tem intenção em propagar essa experiência para que a sociedade crie modelos mais sustentáveis de cuidado? 0 documentário produz em nós uma vontade grande de pertencer a esse propósito." E eu vou emendar a outra pergunta, do Tomás, que também é paliativista, o Tomás Aquino. Ele pergunta: "O que seria esse terreno fértil? Para que essa vivência maravilhosa pudesse ter ocorrido." Mas eu vou pedir um pouquinho a opinião da Manu, a opinião da Denise, a opinião do Peter... para a gente esquentar um pouco mais, porque eu acho que de uma certa forma, o Samir meio que já colocou em pauta essas questões. 0 que a gente pode fazer, não é? E que terreno fértil é esse?

\section{Manuela:}

É importante a lembrança do Peter. Na n-1 edições a gente teve a oportunidade de publicar um relato já sobre a quarentena solidária e fizemos essa revisão histórica da instituição (ver nota $n^{\circ} 12$ ). De maneira breve, sobre o terreno fértil, a história toda que a instituição teve desde a sua criação, foi a partir de uma oportunidade que o Samir teve. Ele foi atrás de outras instituições que cuidavam de idosos e ali já plantou essa semente de valores. Ele viu aquilo que ele não gostaria de fazer, infelizmente. Em torno de 2003. E foi então através do contato com os cuidados paliativos, professor Marco Túlio, 


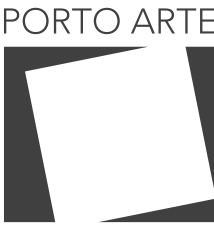

Revista de Artes Visuais

V. $25 n .44$ Jul/dez 2020 e-ISSN: 2179-8001
Figura 4: Paciente e enfermeira de mãos dadas. Still do Filme "Esquina do mundo", 2020. (Direção de João Rocha Rodrigues)
Goretti e tantos outros, figuras importantes, que o Samir viu então que era o caminho que ele gostaria de trilhar. Através do cuidado humano. A gente pode dividir com vocês o link, o acesso é aberto, na n-1 edições, e ali tem um pouquinho da história e desse terreno fértil. Estamos à disposição também para fazer outros relatos desse histórico da instituição, que já foi ali cheio de valores.

\section{Denise:}

Eu vou falar uma coisinha rápida aqui, que tem a ver com o tal do terreno fértil na verdade, que assim, os trabalhadores todos do hospital, em todos os níveis, desde o porteiro, o faxineiro, enfermeiros, todos contam como pessoas singulares e com funções que são conversadas. Eu nunca vi, e frequento hospital por razões de estudo, às vezes tem até um esforço em cuidar dos pacientes de forma - fora do Brasil por exemplo conheço outros hospitais de cuidados paliativos - tem esse esforço dos pacientes contarem na sua biografia e não só como estômago, fígado, cérebro, não só como corpo e organismo, não é? Eles contam a sua biografia, isso o hospital faz. Mas também não faz só isso. Quem conta também são aquelas pessoas que trabalham com... E isso é fundamental, porque os trabalhadores, pelo que eu percebi, pelo que eu conheci nesses dois anos e meio de frequência, eles contavam, eles eram biografias também. Ele não era só o enfermeiro Fulano de Tal. Sabe? A cozinheira, ou sei lá quem. Então, isso valeria para todas as instituições. Seria muito bom escolas, universidades - que é o meu meio - mas outras instituições terem isso. Não é? Você não conta só se você tem uma iniciativa de fazer um projeto lucrativo, não é nesse sentido. Conta quem você é, o que você faz, a sua casa, seu pai, sua mãe... Então, eu tive momentos em que eu pegava a conversa do paciente com o enfermeiro, a outra enfermeira... É isso que é o lar, não é?

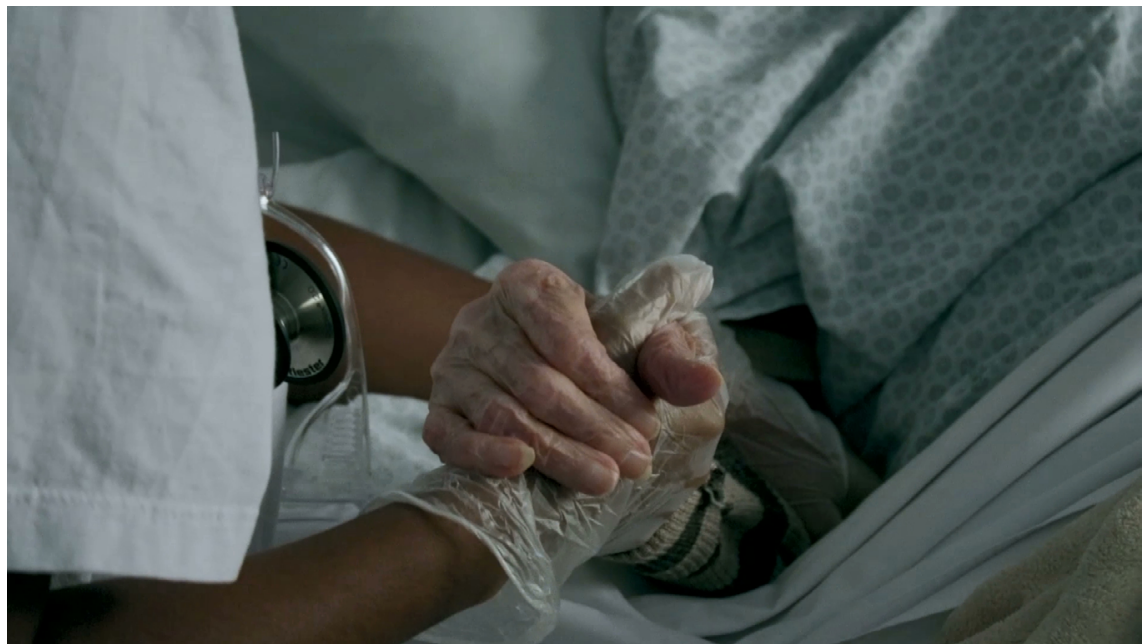




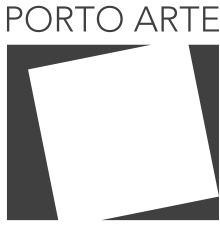

Revista de Artes Visuais

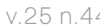

Jul/dez 2020 e-ISSN: 2179-8001

\section{Goretti:}

Tem mais perguntas aqui, mas a gente vai ter que ir encaminhar e depois uma rodada final. Uma está muito fácil de responder. O Christian Douradinhos diz: "O Hospital Premier foi capa do New York Times e de muitos outros jornais. Será que com essa visibilidade nacional e internacional conseguiremos mudar um pouco da nossa realidade cruel nas pequenas ILPI's, do morrer sem qualidade? Superamos todos, não é?"

\section{Peter:}

Eu quero falar uma coisinha muito curta. Claro que eu não posso responder; quem é do Hospital pode responder isso. Mas eu acho que desde o primeiro momento que eu pisei os pés aí, e na primeira conversa com o Samir eu entendi que essa instituição tem uma antena para as alianças possíveis. Uma espécie de antenagem que não fica só dentro do próprio, como o outro chamou, casulo de felicidade. É linda essa expressão. Mas tem uma visão sobre uma rede de conexões que podem aumentar a visibilidade, aumentar a circulação e talvez ir contaminando o entorno. Então, eu sou muito grato ao Samir por ter me aceito como um aliado. E eu acho que a gente pode expandir essas alianças nessa direção que a pergunta apontou. Era isso.

\section{Goretti:}

Perfeito. Samir, a Manu, a Denise e o Peter, só para a gente finalizar a sessão. 0 que a gente leva, e qual é a nossa tarefa? Nós todos que participamos dessa sessão, assistindo, estando aqui falando ou não. Mas qual é a nossa tarefa para levar adiante esse espírito que o hospital traz. De compartilhamento, de solidariedade. 0 que a gente faz além, Samir disse, o que é que você recomenda para a gente, o que a gente vê como tarefa?

\section{Manu:}

Eu continuo com muita gratidão à participação de todos e à contribuição para que a gente ganhe ainda mais fôlego para seguir os próximos meses. Ainda estamos nessa situação muito tensa, principalmente para quem faz parte do grupo de risco, como os nossos pacientes. Desde o início dessa pandemia, quando começamos a poder olhar para as outras questões, não só o foco ali em prevenção da COVID-19 dentro da instituição, mas com o foco também no cuidado da equipe. Os impactos da pandemia atingiram com certeza a todos, então a experiência foi muito intensa. Apesar de muito rica, também muito intensa para todos, e esse é um dos caminhos que a gente vai trilhar. Esperamos sim, como o Christian falou, que a visibilidade dessa experiência possa auxiliar. Mas a gente vai continuar aí militando pelos cuidados paliativos enquanto plano de carreira. Acho que é isso, vamos continuar militando para melhorar a qualidade de vida e de morte para o máximo de brasileiros possível. Acho que é por aí.

\section{Denise:}

A gente tem que fazer efeito multiplicador mesmo. Tem que fazer uma batalha, porque o ambiente é inóspito, no sentido nacional do termo. Não é que eu sou otimista, mas eu vejo que há necessidade, as pessoas querem ter ideias de lugares, de experiências 


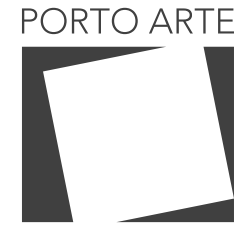

Revista de Artes Visuais

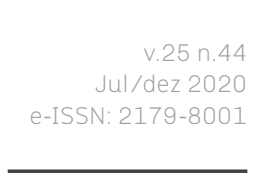

Figura 5: Trompetista e uma paciente do hospital na "Janela dos encontros" para visitas criada pelo Hospital Premier. Still do Filme "Esquina do mundo", 2020. (Direção de João Rocha Rodrigues) que funcionaram e não conhecem. Então eu acho que é agora o momento, sabe? É agora o momento. Depois que passar o vírus a gente faz alguma coisa. Não, não, não. A gente tem que fazer agora. Divulgar o máximo que puder com os canais que tiver acesso, esse tipo de experiência. Obrigada, viu? E um grande beijo a todos. Eu tenho saudade.

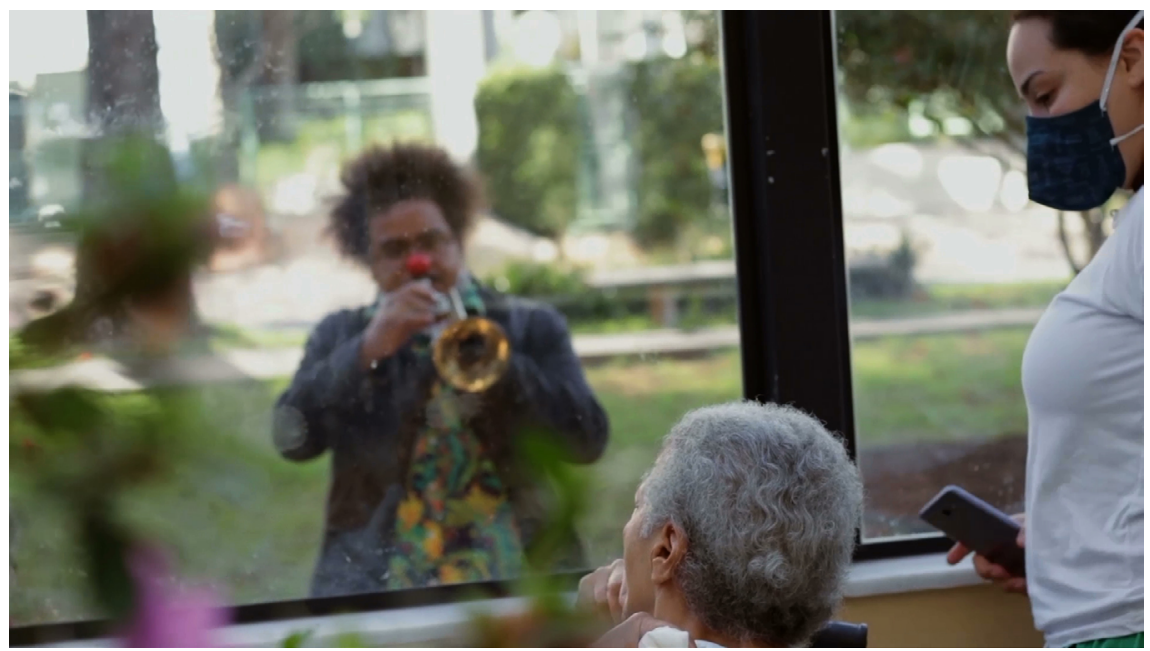

Samir:

Primeiro, agradecer imensamente vocês estarem convivendo e refletindo com a gente sobre essa experiência. É evidente que a gente ainda está no meio dela e vivenciando. Eu saio dessa vivência com os meus compromissos mais aprofundados para tentar tornar esse país um país menos desigual. E entendo que a maior lição que eu tiro, de um exemplo muito simples e rápido: Quando comecei tomar banho no vestiário dos funcionários aqui durante 100 dias, não tinha saboneteira. Aí eu refleti, mas a gente se diz tão humanista, tão bacana, tão legal e não tem a porcaria de uma saboneteira aqui. Eu tô falando uma coisa muito simples, mas que traduz na verdade muito a teoria da prática. Então quando a gente fala que alguém anda 3 horas por dia de ônibus, é uma frase, solta. Vai lá você, senta a sua bunda diariamente, anda 3 horas e vem cuidar do outro. E mantém o "sorriso McDonald's", "ah, estamos todos felizes". A Denise pode nos dar aula sobre isso, sobre a felicidade que as pessoas querem nos impor. Então, a grande pergunta que foi feita é o que eu faria se essas pessoas fossem meus familiares? Minha mãe, meus irmãos... Eu faria o que eu fiz. Então, eu gostaria muito de inspirar as pessoas a exercer a alteridade de fato, de verdade. Não teórica. Não fazer coraçãozinho nas redes sociais e toda essa onda que existe de solidariedade virtual. É solidariedade real. Eu não aceito que uma instituição se auto-denomine de cuidados paliativos e um médico não olhe para a faxineira. Eu não aceito isso. E não estou falando em assistencialismo, em messianismo... É minimamente o respeito humano ao outro. Porque o exercício do cuidado não é protocolar, para mim. Ele é uma atividade incondicional. Eu cuido do paciente, eu cuido do familiar do pa- 


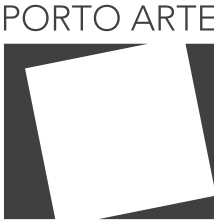

Revista de Artes Visuais

v. 25 n.44 Jul/dez 2020 e-ISSN: 2179-8001
Figura 6: Paciente e seu familiar se encontram pela "Janela dos encontros" para visitas criada pelo Hospital Premier. Still do Filme "Esquina do mundo", 2020. (Direção de João Rocha Rodrigues ciente, eu cuido do meu companheiro de trabalho. E saio dessa experiência com a certeza absoluta de que nós temos que exercer a alteridade de verdade. Quando a gente fala, não é uma coisa abstrata. Essa pessoa que está cuidando do paciente aqui, ela tem uma vida desgraçada. Talvez não esteja sob a nossa governança resolver todos os problemas. Mas só o fato de estar atento e respeitar já é um grande passo para a gente começar a mudar um estado de coisas.

\section{Goretti:}

Peter, agora você tem a responsabilidade, você é a última palavra.

\section{Peter:}

O Samir é um sacana, ele deveria ser o último. Joga o abacaxi aqui. Olha, eu acho que a pior doença que tem nos contaminado é uma espécie de blindagem sensorial. As pessoas estão blindadas e não conseguem ser afetadas pela dor do outro. E o que vocês fizeram é um exercício coletivo de afetação mútua. E não é só... Eu imagino, quando alguém cuida, claro, está olhando, enxergando, mas ele também está cuidando de algo nele. Tem algo na alma dele que sofre uma transformação nesse cuidado. E não é pouco. E essa transformação é, eu diria assim, da ordem de uma ética, sabe? Eu acho que é isso que vocês estão fazendo. E é o que a gente precisa hoje.

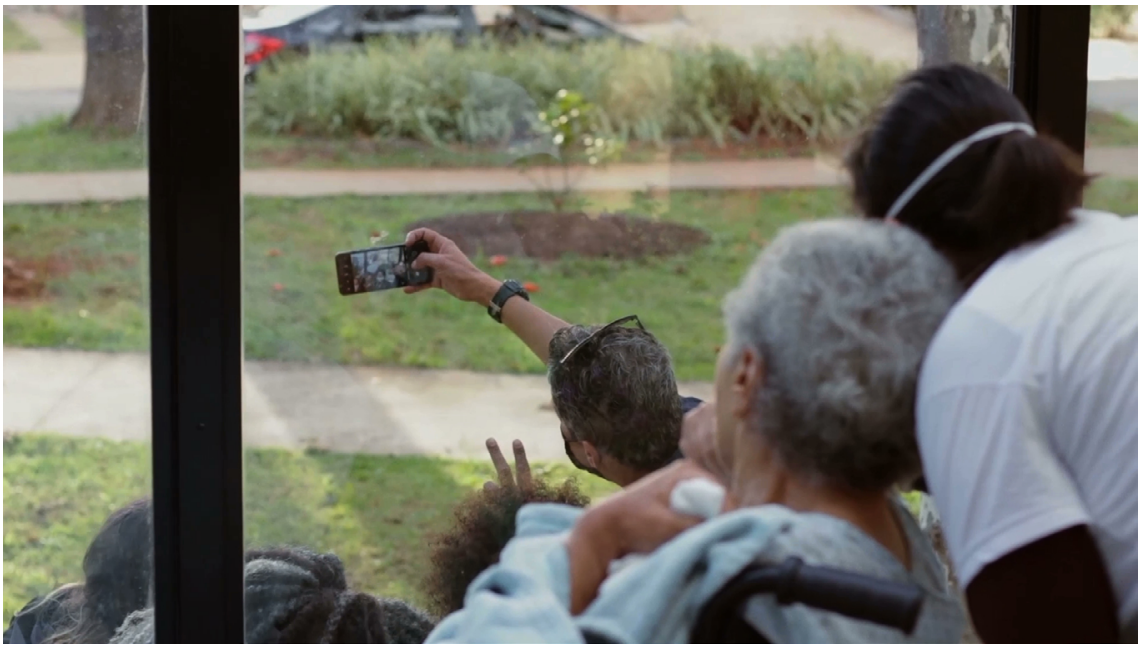

\section{Goretti:}

Nossa, eu super agradeço a oportunidade de estar aqui hoje. Quanta coisa eu aprendo todo dia com vocês. Foi realmente uma enorme honra, Samir, você sempre nos honra. Você é essa pessoa que tem esse espírito que traz, que muda o mundo. A gente sempre brincou que o Samir estava 10 anos à nossa frente e acho que agora ele está uns 120 anos, depois de ter passado por essa experiência. E acho que só posso desejar ao mundo que a nova leva de vírus seja um vírus SAMIR-2, SAMIR-3, SAMIR-4 e que a gente possa ser contaminado com essa vontade, essa ética... Realmente esse 
PORTO ARTE

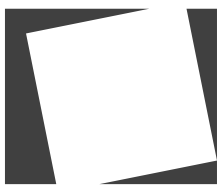

Revista de Artes Visuais

v. 25 n. 44 espírito de colocar em prática valores desses dos quais a gente fala tanto. E a gente vê tão pouco as pessoas porem em prática. Acho que a gente tem que se despedir, não é? Um prazer enorme estar com vocês, muito obrigada a todos, a todas que nos ouviram e que vão ouvir no futuro também. Porque eu espero que esse vídeo seja replicado muitas vezes, e que a gente possa estar juntos muitas outras vezes. Um grande beijo, saúde para todos nós. 


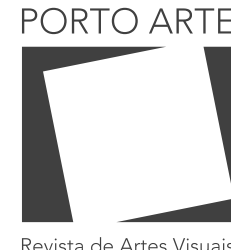

1.25 n. 44 Jul/dez 2020 e-ISSN: 2179-8001

Texto submetido em 23/12/2020 Texto publciado em 24/12/2020

\section{Denise Bernuzzi Sant'anna}

Professora livre-docente de História da PUC-SP. Possui graduação e mestrado em Historia pela Pontifícia Universidade Católica de São Paulo, Diploma de Estudos Avançados em História pela Universidade Paris VII (1990), Doutorado em Histoire des Civilisations Occidentales pela Universite de Paris VII (1994). Atualmente é Coordenadora de área CHS I da Fapesp.

\section{Manuela Samir Maciel Salman}

Médica especializada em Psiquiatria, pós-graduada em em Medicina Paliativa e em Cuidados Paliativos num Modelo de Atenção Integral à Saúde, diretora do Hospital Premier e coordenadora de estágios do Instituto Premier de Educação e Cultura. Facilitadora do Programa QELCA@-Premier, em parceria com o St. Christopher Hospice.

\section{Maria Goretti Maciel}

Diretora do Instituto Paliar. Possui graduação em Medicina pela Universidade Federal de Pernambuco (1983) e especialização em Medicina Geral e Comunitária pela Associação Hospital de Cotia AHC (1986). Atualmente é Diretora de Serviço de Cuidados Paliativos do Instituto de Assistência Médica ao Servidor Público Estadual de São Paulo - IAMSPE e Diretora/Corrdenadora Pedagógica/Professora do Instituto Paliar. É Coordenadora do Programa de Residência em Medicina Paliativa do IAMSPE.

\section{Peter Pál Pelbart}

Professor titular da Pontifícia Universidade Católica de São Paulo (PUC-SP). Possui graduação em Filosofia pela Sorbonne (Paris IV-1983) e doutorado em Filosofia pela Universidade de São Paulo (1996). Trabalha com Filosofia Contemporânea e é ensaísta. Junto a Ricardo Muniz é editor da n-1 edições.

\section{Samir Salman.}

Médico, administrador e idealizador do Hospital Premier, primeiro hospital privado do Brasil integralmente norteado pelos Cuidados Paliativos e o primeiro da América Latina a se tornar instituição satélite do St. Christopher's, hospice britânico berço dos Cuidados Paliativos. Formado pela Faculdade de Medicina de Itajubá (MG) em 1989, além de superintendente do Hospital Premier, Samir também atua como diretor do Instituto Premier de Educação e Cultura, vertente educacional do hospital fundada em outubro de 2018. Participa intensamente em frentes que defendem políticas públicas em questões ligadas ao envelhecimento e aos Cuidados Paliativos. 